\title{
Die Freiwilligenforschung hat mehr zu bieten, als die Praxis wahrnimmt: Ein Fazit zur Flüchtlingshilfe
}

Ein Ineinandergreifen von Forschung und Praxis hätte helfen können, während der Flüchtlingskrise ab Herbst 2015, einiges an Frustration zu vermeiden; sowohl für die NPO und deren professionell sowie ehrenamtlich Tätige, als auch für Geflüchtete. Was ließ sich beobachten? Obwohl die Beteiligungsquoten für die FWA eher rückläufig sind oder stagnieren, ist die Hilfsbereitschaft hoch, wenn es sich um Sportevents, Kirchentage, einen Papstbesuch oder um Umweltkatastrophen handelt. So war es auch bei der Flüchtlingskrise Ende 2015, nur mit dem Unterschied, dass sie länger anhält, als die vorgenannten Begebenheiten und es zur Bewältigung der Aufgaben mehr brauchte und braucht als spontanes Hilfeverhalten.

Aus Sicht der Freiwilligenforschung wurden in der Flüchtlingskrise zweierlei deutlich:

1. Freiwilligenarbeit ist stärker vom gesellschaftlichen Kontext abhängig, als dies bis dahin beobachtbar war. Manche, vor allem früher nicht engagierte Bürger gerieten in Konflikte mit sich selbst (Wie stehe ich, meine Familie und andere zur Flüchtlingspolitik?) und in Spannung zu den anderen Akteuren (Schaffen wir das wirklich? Das muss man anders organisieren! Wo bleibt die Dankbarkeit der Geflüchteten?).

2. Gerechtigkeitsvorstellungen spielen eine maßgebliche Rolle. Zu berücksichtigen sind nicht nur Hilfeempfänger (Geflüchtete) und diejenigen, die freiwillige Arbeit leisten, sondern auch die Nichtengagierten. Die Gerechtigkeitsvorstellungen zwischen Nichtengagierten und Engagierten unterscheiden sich deutlich. „Gerechtigkeitswahrnehmungen sind daher im Kontext der Flüchtlingshilfe ernst zu nehmen, um Konflikte zu entschärfen " (Strubel und Kals 2018, S. 40).

Praxis braucht Forschung, Forschung braucht Praxis, so das Fazit unseres wissenschaftlichen Arbeitens. 